- labelling health warnings on packages;

- taxation;

- the illicit tobacco trade;

- regulation of contents, ingredients, nicotine levels, additives and poisons found in tobacco.

\section{WORKING AS ATEAM}

In addition to the NSW Department of Health, there are many other stakeholders within NSW who are actively involved in the implementation of the draft Tobacco Action Plan 2001-2004. These include other government departments and non-government organisations such as the Cancer Council of NSW, the National Heart Foundation of Australia (NSW Division), and anti-smoking groups. The Tobacco Control Network was established in 2000 under the draft Tobacco Action Plan 2001-2004, with the aim of bringing together a large group of people who work on tobacco control to share information and ideas and to work collaboratively on projects aimed at reducing tobacco related harm.

The Tobacco Legislation Compliance (TLC) group, also formed as part of the plan, examines issues relating to the implementation of legislation and related programs such as the sales to minors program, enforcement of advertising laws and the introduction of smoke free public places legislation.

For further information on any of the above initiatives contact the Tobacco and Health Unit, NSW Department of Health, 73 Miller Street, North Sydney, NSW 2060; telephone: (02) 9391 9268; facsimile: (02) 9391 9579; or email: coneil@doh.health.nsw.gov.au.

\section{REFERENCES}

1. English DR, Holman CDJ, Milne MG et al. The quantification of drug caused morbidity and mortality in Australia. Canberra: Commonwealth Department of Human Services and Health, 1995.

2. Winstanley M, Woodward S and Walker N. Tobacco in Australia: Facts and Issues. Melbourne: Quit Victoria, 1995.

3. Commonwealth of Australia. Australia's National Tobacco Campaign Evaluation Report: Volume One Every cigarette is doing you damage. Canberra: Commonwealth Dept of Health and Aged Care, 1999. w

\title{
ADVOCACY FOR TOBACCO CONTROL
}

\section{Andrew Penman}

Chief Executive Officer

NSW Cancer Council

Although Australia is regarded as an example of best practice in tobacco control, the failure to achieve substantial reductions in smoking prevalence throughout the 1990s has been a source of frustration to its exponents. Not that the tobacco industry has had it all its own way:

- relatively constant prevalence belies significant drops in aggregate cigarette consumption;

- off-pack cigarette advertising has been virtually abolished;

- greater control is being exercised over sales to minors;

- nicotine replacement therapy can now be publicly promoted and is available over-the-counter;

- we have entered the new millennium with most public places now smoke free, and there is a very real commitment on the part of many governments to finishing this particular job.

But in some respects, it is striking how effectively the tobacco industry has turned political opinion on issues of central importance to it. The Corporate Affairs Plan of October 1992 for Philip Morris (Australia) Limited proposed to divert the Ministerial Council on Drug
Strategy from its 'misplaced' priority on tobacco towards illicit drugs. ${ }^{1}$ Anti-smoking campaigns were to be focused on youth, with the industry preferably taking a leading role according to this plan. This agenda was to be supported with 'enhanced' political connectivity, alliances with other industry groups, and the representation of Philip Morris as 'Philip Morris companies', not 'Philip Morris, the tobacco company'. Doubtless, enhanced connectivity would have carried a powerful message about the contribution of tobacco to the Australian economy.

In these circumstances, the interest of public health groups in developing new approaches to supplement the established portfolio of smoking abatement measures is understandable. Of these, litigation and regulation have been the most promoted. This article reviews the current role of litigation and regulation in tobacco control, and suggests other measures that can be taken to reduce tobacco smoking.

\section{LITIGATION}

The 11th World Conference on Tobacco or Health (WCTOH) was recently held in Chicago in the afterglow of the award of punitive damages in the case of Engle versus Reynolds Tobacco Company. So it is scarcely surprising that litigation ranked high on the conference 
agenda, and that it was hailed it as a new force for changing the face of tobacco control globally.

Had the industry been on trial at the 11th WCTOH, there would have been little doubt about the verdict. Indeed, the scale, variety and sophistication of the tobacco companies' deception is breathtaking, as is their indifference to the health of their customers. Industry documents reveal a deliberate global strategy to create and sustain public controversy over the relationship of smoking to health. The tobacco industry has indicated that it has created a so-called smoking and health controversy while possessing the knowledge to resolve it; and it has designed cigarettes that are more effective in establishing addiction, and marketed light cigarettes as a means of reassuring smokers and dissuading them from quitting.

The key questions are whether a court of law will deliver judgement in the same way, and whether a judgment will enforce business penalties on the industry that are favourable to public health. The prospect of recovering money to finance health care for people with tobaccorelated diseases has a clear public health benefit. However, no third party action has yet won a favourable judgement, with the action run by the United States Attorneys-General being settled prior to judgment. In Australia, the current action by the Tobacco Control Coalition has as one object: the creation of a fund to support comprehensive national smoking abatement measures; but almost all other cases, here and overseas, have been concerned with damages for smoking-related disorders.

There is no doubt that tobacco industry defence in litigation has been dealt a blow by the revelations contained in company documents. It is a pity that discovery in the United States did not extend to issues such as marketing to children, and that the documents obtained from the British American Tobacco Company (BAT) remain difficult to access. However, what is available has served to destroy the core defence of the tobacco industry: that is, the assumption of risk. This doctrine precludes recovery when a plaintiff subjectively appreciated a risk and voluntarily encountered and accepted the risk. A 1977 document of the BAT is one of many that showed the industry's growing appreciation of the role of addiction in smoking behaviour, ${ }^{2}$ and their subsequent manipulation of nicotine delivery in 'low' delivery cigarettes shows how they exploited this.

The marketing of low tar and nicotine cigarettes (TNC) has been another area of vulnerability exposed by tobacco industry documents. The industry privately held the view that low tar cigarettes could not be held to be safer, but successfully marketed the proposition that they were an alternative to quitting. Population surveys conducted by the American Cancer Society suggest that the 'low TNC' era has been associated with an increase in the rate of lung cancer among smokers. ${ }^{3}$ It was a period through which the cigarette became an increasingly engineered product, and the companies acquired a mountain of internal scientific knowledge showing the harm that this might cause. Smoker compensation is perhaps the best known of these effects, but they include a lowering of aerosol particle size, ventilation hole blocking, and indifference to results of mutagenicity tests on tobacco smoke.

Yet success in a damages action remains challenging. The tobacco industry has been repeatedly successful in challenging the role of tobacco in causing cancer in individual plaintiffs. Even in NSW there are so-called expert witnesses who are happy to argue all manner of arcane alternatives. But damages need to be pressed on a mass scale if they are to seriously wound the industry. The success of a class action in Engle versus Reynolds Tobacco Company was therefore most encouraging, but it must yet survive on appeal. The recent attempt in Nixon versus Philip Morris to mount a class action in the Australian Federal Court failed before the appeal bench earlier this year.

\section{REGULATION}

When industry documents revealed how the industry had effectively manipulated the cigarette as a drug delivery device, the United States Food and Drug Administration began a sustained attempt to bring tobacco under its jurisdiction. If successful, and if an effective regulatory scheme were available, this may have been a powerful new tool in the tobacco control portfolio. However, the effort failed in the United States Supreme Court, and barring specific action by Congress, seems to be stalled.

There is an intuitive appeal in the proposition that the constituents of tobacco may be regulated to reduce or eliminate harm. The level of harmful constituents in tobacco or its pyrolysis products could be reduced, subject to the availability of means; additives could be subject to similar controls to food additives; and nicotine might be lowered to make cigarettes progressively less addictive, to the point of consumer refusal. Alternatively, nicotine levels might be liberalised to reduce the aerosol dose required for health effect and taste.

The Draft of the NSW Tobacco Action Plan (TAP) released for public consultation earlier this year has, for the first time, included tobacco product regulation as a key focus area. NSW recognises the Commonwealth Government as the lead agency in this field and plans to collaborate with them in the area of labelling of health warnings and the disclosure of contents of tobacco products. These issues have been explored in a consultation document circulated by the Commonwealth Government. ${ }^{4}$

It is sobering to realise that the delivery of low tar and nicotine cigarettes was initially championed by health 
authorities, and imposed by regulation. The tobacco industry became more enthusiastic proponents when they realised the marketing advantages. This experience highlights the difficulties when faced with an industry whose global scientific knowledge and technical capacity cannot feasibly be matched without investment well beyond that which Australian governments have been prepared to spend, and where a regulatory scheme would effectively sanction a huge population health experiment whose effects may take years to evaluate.

\section{OTHER MEASURES}

The purpose of the forgoing discussion has not been to discount new strategies, but to reflect on the high degree of uncertainty surrounding their outcome. It is not inappropriate to incorporate higher risk and developmental elements in an overall public health portfolio. The key issue is how program resources should be allocated across the portfolio.

The NSW TAP affirms the effectiveness of early campaigns in this country. The recent National Tobacco Campaign, and the experience of California and Massachusetts, demonstrate that smoking prevalence can be quite rapidly reduced to levels well below what we have achieved with expenditures that are modest in health terms. It may well be that there are limits to the effect and reach of such campaigns. But at that point, with the constituency for smoking reduced by the decline in smoking rates, and the constituency against smoking mobilised through the campaigns, such measures may be more achievable. It is little wonder that the tobacco industry buried a research report in 1977 that documented the effectiveness of antitobacco advertising. ${ }^{5}$

It is a weakness of the smoking and health movement in Australia that it is seen by other sectors, and particularly by other portfolios in government, as a matter exclusively for the health portfolio. It is now a relatively simple matter for the industry to build a constituency among other portfolios, whether by playing on the contribution of tobacco to the economy, its false notions of market freedom, or its spurious claims to supply a 'legal' product.
The NSW Department of Fair Trading administers an admirable piece of legislation, the Fair Trading Act 1987. Among its provisions are sanctions against misleading and deceptive conduct, the establishment of product safety committees, and provision for the recall of defective goods. At the Commonwealth level, there is similar power to recall defective products, while the powers of the Australian Competition \& Consumer Commission under the Trade Practices Act are considerable. There may be opportunities to collaborate with the small business sector to restructure the retail tobacco industry; to revisit a licensing scheme; and to raise economic issues with the Commonwealth Treasurer in the light of the World Bank report Curbing the Epidemic. Finally, the relationship of tobacco to the protection of children, the welfare of prisoners, and to other drug use, deserves an airing within government.

As 'tobacco or health' is now a major social movement, it is scarcely surprising that new ideas and opportunities to advance its goals are being promoted. However, this should not blind the public health community to the importance of committing most resources to measures that are proven to work and that involve least risk to the community.

\section{REFERENCES}

1. Philip Morris (Australia) Ltd. Corporate Affairs PlanOctober 1992. www.pmdocs.com Bates No. 2023240608/ 0627.

2. Thornton R. Dependence on Cigarettes Smoking - A Review. British American Tobacco Company-December 1977. www.hlth.gov.bc.ca/guildford Bates No. 00095126.

3. Thun MJ, et al. Cigarette Smoking and Changes in the Histopathology of Lung Cancer. J Natl Cancer Inst 1997; 89:1580-1586.

4. Scollo M and Chapman S (editors). Tobacco Control in Australia: a priority-driven research agenda. Sydney: National Heart Foundation of Australia and Australian Cancer Society, 1999.

5. Defence of Advertising. Committee Report to International Committee on Smoking Issues. July 1981. www.pmdocs.com Bates No. 2025048102-8105. it?

\section{COCHRANE COLLABORATION HEALTH PROMOTION AND PUBLIC HEALTH WEBSITE}

The Cochrane Collaboration has established a Health Promotion and Public Health specialty Field to promote the production, dissemination and use of systematic reviews of the effectiveness of health promotion and public health interventions: Compiling best available evidence to guide practice and policy is the motivation, the challenge and the nexus of the work of our Field.

Elizabeth Waters, Director, Research and Public Health Unit, Department of Paediatrics, Royal Children's Hospital, Melbourne, is one of the two Field Coordinators.

Further details about the activities of the Field, how to contribute to it, how to receive the Field's electronic newsletter, etc. can obtained from the website: http://vhpax.vichealth.vic.gov.au/cochrane. 